\title{
Inside Zimbabwe's cholera epidemic
}

Published at www.cmaj.ca on Dec. 15, 2008.

I am feeling a little uncomfortable," says the middle-aged man lying in the dirt behind the main hospital in Beitbridge, Zimbabwe.

His name is Henry. He is so dehydrated his cheeks look collapsed and his eyes protrude from his closely cropped skull. Médicins Sans Frontières (MSF) nurse Clara Chamizo is struck by the absurdity of the notion that Henry is feeling only a little uncomfortable lying on the ground, amidst the dozens of cholera patients who have overwhelmed this border town of 40000 like a wildfire.

"Normally, cholera starts with a few cases, and then we have the peak after a few weeks," says MSF Emergency Coordinator Luis Maria Tello.
That is not the case in Beitbridge, a town of about 20000 people, $527 \mathrm{~km}$ south of Harare on the border of South Africa. On Nov. 14, 2008, Zimbabwe health authorities reported 5 cases. Two days later, there were 500. Now, 2 weeks later, there are 1500 , and there is no sign the exponential growth will end. Tello surmises that they all "got the cholera from the same source at the same time."

Initially, patients were placed inside the hospital, with most lying on the floor. With only 1 or 2 cleaning staff, the hospital toilets quickly backed up. There was also a shortage of cleaning supplies and water, and the level of hygiene quickly deteriorated.

By Sunday, the hospital started moving patients out onto the dirt com- pound, so that their body excretions could be absorbed into the ground.

The sight is appalling. People lie in the dust under scorching 45-degree heat. They plead for the "life-saving" drip (ringer lactate IV fluid). There isn't even water for them, as the hospital has its supply cut most days.

MSF Project Coordinator Dr. Veronica Nicola, an Argentine pediatrician, says she has never inserted so many catheters in any day in her life. "For me the hardest thing was to be able to concentrate on one person. There was a man lying next to one of the trolleys under the sun. By the time I got to him he was in shock. We tried to get a vein like 10 times, but then he started gasping and he died right there in front of our eyes."

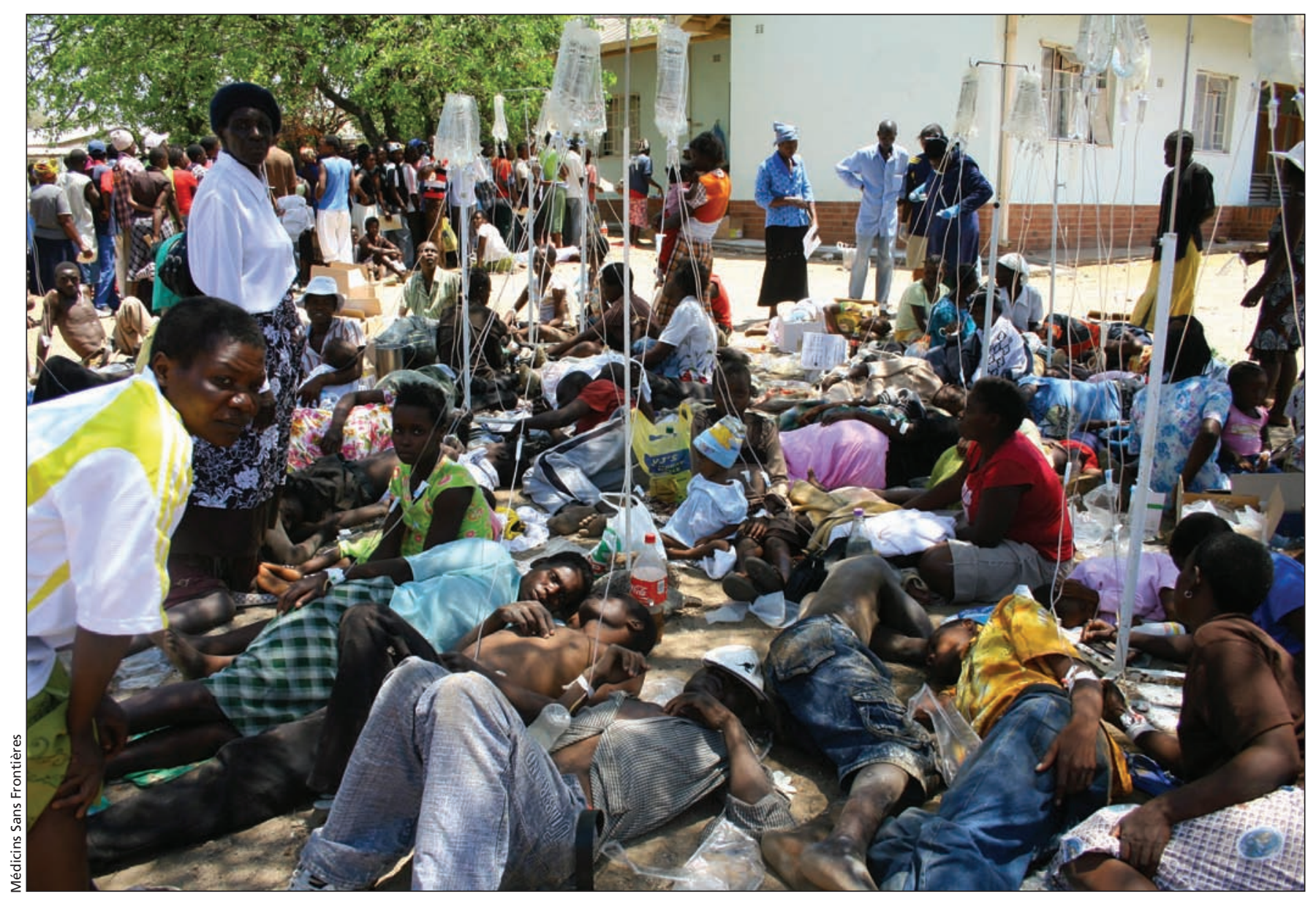

Cholera patients are treated in the backyard of the hospital in Beitbridge, Zimbabwe. 
She pauses.

"If I had seen him half an hour before, we might have been able to do something about it, but there were so many people lying there, people calling you. But still, we could have done something."

In one week, 54 people died. The hospital did not have IV fluid or oral rehydration salts tablets in stock. MSF shipped more than 800 litres of ringer the first day of the intervention and many more litres since. Twelve shipments of medical and logistical supplies arrived in 10 days. A 16-strong MSF team was dispatched to Beitbridge and more than 100 local health workers and cleaners have been hired.

Within 3 days, a cholera treatment centre with 130 specialized beds they have a hole in the middle, under which a bucket is placed to collect diarrhea - was set up.

The only treatment is to give a person enough fluids to survive until the bacteria's life cycle expires, typically 5 days. Without those fluids, a person can die within hours.

Hygiene is the only means of prevention. Within 2 days of the outbreak, a MSF car with 2 officials from Zim- babwe's Environmental Health Office, travelled through the town, delivering public health information through a loudspeaker.

Angry crowds gathered to shout:

"How do you expect us to control cholera when there is no water!"

"Look at this sewage running here right next to us!"

"Why don't you clean up the garbage in the streets?"

It is a migrant town, with a shifting tide of truckers, sex workers, unaccompanied children and desperate people seeking better lives, mostly by attempting to cross the border into South Africa. Sewage runs through the streets. Every day there are water outages, power outages and outages of hope.

A MSF car pulls off the highway into an area where truckers wait for customs clearance to cross the border to South Africa. The truckers are as angry as the local residents. They show us the cesspool where they wash their hands and the adjoining field covered in human excrement. "Where are we supposed to go?" asks one man.

The water station doesn't have the parts to repair the pump needed to bring water from a tower to the town.
Even if it did, it takes electricity to run the pumps, electricity generated with coal from a coal mine that no longer supplies coal. The mine workers haven't been paid in a year. Neither have the garbage collectors. The sewage facility is in a similar fix. There is no solution in sight. - Alois Hug, Beitbridge, Zimbabwe

Cholera update: As of Jan. 8, 2009, there were 35931 people with cholera in Zimbabwe and 1778 residents had died as a result of the epidemic, according to the World Health Organization. All 10 provinces have been hit and United Nations aid agencies have warned that the number of cases could top 60000 .

DOI:10.1503/cmaj.081964

CMAJ invites contributions to "Dispatches from the medical front," in which physicians and other health care providers offer eyewitness glimpses of medical frontiers, whether defined by location or intervention. Submissions, which must run a maximum 400 words, should be forwarded to: wayne.kondro@cmaj.ca

\section{Briefly}

Measles mortality falling: In 2007, 197000 people died from measles, down from 750000 in 2000. The Measles Initiative (www.measles initiative.org), an organization that provides support for vaccination campaigns and disease surveillance, stated in a De-

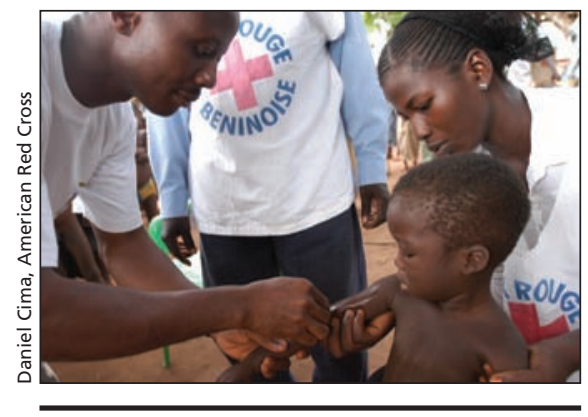

Despite a concerted effort, measles still takes a deadly toll. In 2007, 197000 people died worldwide after contracting the vaccine-preventable disease. cember 2008 report that $63 \%$ of the global reduction took place in Africa, largely due to immunization efforts. The Eastern Mediterranean showed the largest overall reduction, with a decrease of $90 \%$. "The progress that has been made shows what can be achieved through measles vaccination campaigns, but much more needs to be done," UNICEF's Executive Director, Ann M. Veneman, stated in a media release. Progress has been slower in countries such as India - which accounts for one-third of measles-related deaths worldwide - due to delays in the implementation of large-scale vaccination campaigns.

Green group: Medical Students for Environmental Health has been founded by University of Alberta medical student Sean Welling to combat the "gross deficiency in education and student advocacy groups regarding the medical im- pacts of the environment on health." The group aims to raise awareness within the school and the medical community about the many ways the environment affects human health. Welling says he hopes this will one day be part of medical school curriculums: "As future physicians, we should know how the air we breathe, the water we drink and the food we eat affects our health."

Hold the cold meds: Children under 6 years old should not be given cough and cold medications, according to a Health Canada decision on labelling on Dec. 18, 2008. The statement warns of potential severe side effects, based on numerous severe reactions January 1995-2008 (www.hc-sc.gc.ca/ahc-asc /media/advisories-avis/_2008/2008_184 -eng.php). — David Manly and Erika Gilbert, Ottawa, Ont.

DOI:10.1503/cmaj.090015 